\title{
How Students Self-Prepare for a Study-Abroad Program: A Qualitative Analysis
}

\author{
Nilufer Medora,Ph.D \\ Professor \\ California State University, Long Beach \\ Department of Family and Consumer Sciences \\ United States of America \\ Tiffany L. Brown, Ph.D \\ Associate Professor \\ California State University, Long Beach \\ Department of Family and Consumer Sciences \\ United States of America \\ Sarah Taylor, Ph.D \\ Assistant Professor \\ California State University, Long Beach \\ Department of Family and Consumer Sciences \\ United States of America
}

\begin{abstract}
With increasing globalization and cultural interconnectedess, higher education is putting more effort into developing and encouraging students to particiapte in study abroad programs. In recent years, researchers have also paid more attention to identifying how to best prepare students for their study abroad expereinces, yet, there has not been an investigation of how students self-prepare prior to a study abroad excursion. Using the narratives of 80 college students, the present study examined student perceptions of their preparatory efforts prior to the "Semester at Sea" (SAS) study abroad voyage.Six major themes emerged from the data as students reported preparing in the following ways: 1.) Acquiring Knowledge; 2.) Financial Preparation; 3.) Logistical Preparation; 4.) Relational Preparation; 5.) Cognitive Preparation; and 6.) No Preparation/Reliance on Previous Experiences.The findings from this study have utility for future empirical investigations of study abroad programs, as well as for improving student preparatory activities.
\end{abstract}

Keywords: Study Abroad, Semester at Sea (SAS), Student Preparation, Global Studies

The world today is increasingly characterized by unprecedented economic, cultural, political, technological, and social interconnectedness (Luo \& Jamieson-Drake, 2016). Consequently, study abroad programs are receiving renewed attention in higher education as educators try to internationalize their curriculum. Global learning initiatives are also receiving greater recognition and gaining popularity in all disciplines, especially in business, social work, health science, and in the social sciences. Many companies and human service agencies are hiring employees who have had some international travel experience, and are familiar with issues of globalization and cultural diversity, so that they are able to work more effectively with international clients (Harder et al., 2015).

In the social sciences and the human services fields, it is of paramount importance that students are knowledgeable and aware of cultural similarities and differences. Educators and social service agencies workclosely with immigrant families from different parts of the world, refugee populations, as well as multi-ethnic and bi-racial individuals and families. Therefore, it is imperative that students entering the helping professions be qualified with the skills and experiences that foster openness to diversity, cultural sensitivity and a multicultural worldview. Furthermore, high levels of multiculturalism have also been linked to one's personal development, resulting inless prejudiced attitudes (Rios \& Wynn, 2016), higher levels ofaltruism (Fietzer, Ponterotto, Jackson, \&Bolgatz, 2016), and increased creative problem solving strategies (Leung, Maddux, Galinsky, \& Chiu, 2008). One means by which to cultivate multiculturalism, cultural sensitivity, and global mindedness is through global education experiences and study abroad programs (Harris, Kumaran, Harris, Moen, \& Visconti, 2019). 
Researchers have demonstrated a wide variety of advantages and benefits that students gain from participating in study abroad programs. For example, students return with increased global competency (Luo, \& Jamieson-Drake, 2016), as their outlook on global and political issues alters (Lumkes, Hallett, \&Vallade, 2012).Students also demonstrate enhanced global leadership skills (Montgomery \&Arensdorf, 2012), while their openness to diversity (Fang \& Baker, 2018) and cultural sensitivity increases (Medora \& Roy, 2017).

Moreover, scholars have also found that when students studyabroad,their desire to study abroad again is enhanced (Lewis \&Niesenbaum, 2005), as well as their career development and advancement(Norris \& Gillespie, 2012). In light of the increasing need to instill cultural sensitivity and global mindedness in our future educators and human service professionals, researchers have dedicated extensive efforts towards unpacking best practices for study abroad programs (Medora \& Roy, 2017), the factors associated with study abroad participation (Bikos, Manning, \&Frieders, 2019), as well as student outcomes resulting from study abroad participation (Harris et al., 2019). More specifically, there has been considerable attention paid to the pre-departure experiences of students prior to travel with a specific focuson how faculty, institutions, and study abroad programs can best prepare students for their global education experiences (Dunlap \&Mapp, 2017; Goldoni, 2015). Yet, there has been minimal attention paid to how students self-prepare themselves prior to study abroad excursions. To address this gap in the scholarship, the current study will examine student perceptions of their preparatory efforts prior to the "Semester at Sea"(SAS) study abroad voyage. Generating more knowledge on how students prepare will give insight into the areas of preparation that students focus on, as well as the areas that need more attention from students and facultyprior to study abroad departure. The findings from this investigation can inform the structure and curriculum of study abroad programming, as well as provide a foundation for more nuancedempirical examinations of student preparation for study abroad experiences.

\section{Pre-departure Preparation for Study Abroad Programs}

There are clear connections in the research linking the quality of pre-departure preparation with the experiences that students have while abroad, as well as withstudent outcomes after returning from abroad (Dunlap \&Mapp, 2017). Moreover, scholars have suggested that the lack of effective preparation can result in students not receiving the full range of benefits associated with global education experiences (Dunlap \&Mapp, 2017; Kruse \& Brubaker, 2007). A lack of preparation has also been linked to studentshaving difficulty connecting with the host culture, as well as challenges in managing cultural differences (Goldini, 2015). Furthermore, the absence of comprehensive pre-departure preparation may result in negative experiences abroad leading to more ethnocentrism and stereotyped perspectives (Jones, Rowe, \& Miles, 2018). Although most students attend at least one orientation meeting prior to their studyabroad experience, these orientation meetings primarily focus on logistical planning (e.g. health, safety, etc.) for the trip (Kruse \& Brubaker, 2007). While these administrative (visas, medical paperwork, etc.) tasks are important to facilitating a positive study abroad experience, there are several other important preparatory activities that warrant attention prior to departure. A study conducted by Dunlap and Mapp (2017) examined the impact of a semester long pre-departure study abroad courseon student outcomes. The course was structured around theories of intercultural development, which encouraged students to critically assess their own culture, their motivations for their participation in study abroad,andtheir "place in the world" in respect to others (Dunlap \&Mapp, 2017). Data on cross-cultural adaptability was collected from students at three points; on the first and last day of the pre-departure class, as well as one year after the students completed the study abroad trip. The study also included a non-randomized comparison group, which consisted of students who did not take the pre-departure class but traveled abroad. Findings from this investigation demonstrated significant differences between the students who participated in the pre-departure class and those who did not. Overall, the students that participated in the pre-departure course experienced more gains in intercultural competencecompared tothose who did not take the course(Dunlap and Mapp, 2017). These findings support the importance of thoughtful student preparation that includes critical self-reflection and goes beyond the practical and logistical planning (e.g. safety, vaccines, packing, visas, etc.).

Although scholars (Dunlap \&Mapp, 2017; Medora \& Roy, 2017) report the benefit of having pre-departure classes to prepare students for their study abroad programs, there are some study abroad programs like the one targeted for this study (i.e., Semester at Sea) where students come from various institutions across the world and are not able to participate in formal pre-departure classes. In these cases, students will need to do a considerable amount of their preparation on their own. However, after a review of the existing scholarship, the researchers noted that there is a paucity of published empirical data on how students self-prepare and independently navigate the preparation process for study abroad experiences.

\section{The History and Structure of the Semester at Sea Program (SAS)}

TheSemester at Sea (SAS) is a unique study-abroad program, as the entire program is conducted on a cruise ship that has been converted into a floating and functional university. Since the inception of the program in 1963, the program 
has served over 75,000 undergraduate students. The ship circumnavigates the world and makes 4 to 5 day stops at different ports; totaling 10 to 12 ports in one semester. Typically, SAS has approximately 600 undergraduate students on the ship during one semester, coming from approximately 280 universities worldwide. Although limited, empirical studies on SAS have found that after the voyage, studentswere able to better comprehend cultural differences, demonstrated an increased interest and awareness of world events (McCabe, 1994), and reported positive personal growth decades after completing the program (Dukes, 2006). For more information regarding the history and structure of SAS please visit their website (https://www.semesteratsea.org/contact/about-us).

SAS prepares students for the 4-month program by sharing detailed lists of information students need to know and take with them for the voyage. It is impossible for the SAS program to have pre-departure preparation classes for all 600 students from different campuses across the country who plan to participate in a particular voyage. Therefore, there are separate web-links withinformation about the overall program, how to get to the ship, how to obtain visas, packing lists, differentways to keep in touch with family and friends, and medications that are recommended. Likewise, food optionsavailable on the ship, the significance of pre-port lecturers, how to do laundry, and additional information pertaining to the voyage is available on the SASwebsite.

\section{Objectives of the Current Study}

Due to the paucity of research examining students'perceptions of how they prepare themselves for study abroad programs, as well as the important empirical and theoretical connections drawn between preparation and positive student outcomes (Dunlap \&Mapp, 2017), the current study will investigate how students self-prepared for their SAS study abroad voyage. Examining the ways that students reportedly prepare for their study abroad experiences will inform future empirical investigations of study abroad programming, as well as provide insight into how to improve the preparatory activities prior to a study abroad excursion.

\section{Methods}

\section{Procedures and Participants}

The present study took place on a Semester at Sea voyage where students spent a semester visiting several destinations across the world including: Mexico, Hawaii, Japan, China, Vietnam, Cambodia, Myanmar, India, South Africa, Ghana, Morocco, and Germany. The sample for this study consisted of 80 college studentsthat were between $18-23$ years of age $(M=20.23, S D 1.09)$. The majority of studentswere female $(n=63,87 \%)$.Additionally, most were White $(n=52$, $71 \%$ ), followed by 8 percent reporting being Asian, 11 percent indentifying as Latino, and a few student participants identified themselves belonging to two or more races $(n=5,7 \%)$. Additionally, two students stated that they were African-American and one student indcated being Pacific Islander. More than 60 percent of the students were born in the United States and all participants reported that they had prevous expereince traveling abroad. Although there were students at various levels of their acadmic career, the majorty of students were juniors $(n=34,47 \%)$, followed by sophomores $(\mathrm{n}=16,22 \%)$ and seniors $(15,21 \%)$. Data for this study were collected using a questionnaire administered at two-time points over the semester. The initial survey was administered at the beginning of the voyage, and the second survey was administered at the end of the voyage. Both surveys consisted of the same demographic questions regarding race/ethnicity, age, major and GPA, questions regarding past international travel experiences, and measures of participants' global-mindedness and cultural sensitivity. However, the survey administered at the beginning of the voyage included an open-ended question that asked students to report on the ways they prepared for the SAS excursion.

\section{Data Analysis}

The data set, which consisted of 80 short answer responses, described the self-appraised activities that students engaged in to prepare for their SAS voyage. Three members of the research team completed coding of the data using qualitative content analysis techniques. Each comment was assigned a code based on messages conveyed in participants' responses (Eisner, 1998). When more than one idea was expressed in a comment, multiple codes were assigned. During the first stage of the data coding process, the researchers worked independently to identify themes and subthemes. Subsequently, the research team met to compare their categorization of the data into themes and subthemes. When there was agreement, the theme and subthemes were adopted. When there was disagreement or dissent, the issue was discussed, until consensus was reached. The research team also calculated the percentage of respondents who endorsed particular themes. This provided frequency data on which methods of preparation were utilized most and those that wereutilized least by the study participants.

\section{Results}

Overall, a majority of the participants reported engaging in some type of self-preparation prior to the SAS voyage. Six major themes emerged along with severalsub-themes. The major themes for the question "How did you prepare for the SASvoyage?" were: 1.) Acquired Knowledge; 2.) Financial Preparation; 3.) Logistical Preparation; 4.) Relational 
Preparation;5.) Cognitive Preparation; and 6.)No Preparation/Reliance on Previous Experiences. Details of each theme are described below.

\section{Acquired Knowledge}

The most commonly noted method of preparing for the SAS program was acquiring knowledge. This approach to preparation was reported by $66 \%$ of students.

Overall, students acquired knowledge directly from the SAS program, by talking with peerswho had participated in previous SAS voyages, and by gathering research through SAS online websites. A large majority of the respondents specified that they gathered information on various topics directly from the SASprogram. Some students read information related to the voyage that was posted on the SASwebsite. Another preparation activity that was mentioned by some students was attending the SAS orientation meetings held by the Study Abroad office on their campus. One student stated,

"I attended one SAS pre-departure orientation program that was given by an SAS regional specialist who visited our school campus. We were advised to consult the SAS website because most of the students' questions have responses on this website."

Many students conducted their own online research to prepare themselves for the voyage.The study participants reportedusingYouTube and Google to search, read about, and watch videos related to the countries they were going to visit, as well as to find out more information aboutthe SAS program in general. One student mentioned that they "looked up some things to do in the countries we were going to visit," while other students "watched videos about studying abroad." This sub-theme is summarized by one student who said he "[looked] up countries and programs through the internet, read blogs, and saw videos on YouTube."

Finally, other students specified that they talked to "peers" and "alumni" who had previously participated in SAS voyages. Some students talked in-person with peers who had participated in SAS previously. Other students read "blogs written by past participants," as well as researched previous students' reviews and recommendations for the program.

\section{Logistical Preparations}

The second theme that emerged pertained to students' logistical preparations that they conductedprior to the voyage. Overall, twenty-three students $(28.7 \%)$ reported preparation activities related to this theme. Findings in this themeincluded both administrativelogistical preparations, as well as health-related logistical preparations. For instance, students who reported administrative logistics discussedobtaining the appropriate documentation for travel (e.g., Visas), as well as completing the forms and paperwork required by the program. Students also made sure they "could stay on track for graduation" and had their "credits and reports at school" organized prior to the voyage. Furthermore, many students noted their packing preparations and discussed that they spent time deciding what they needed to pack for their voyage. Finally, many students discussed that they spent time preparing for their physical health and medical needs prior to leaving. Students mentioned that they "went to the doctor for meds," "took the necessary [vaccines]," and "purchased essential medicines."

\section{Financial Preparation}

Thethird theme that emerged regarding how participants prepared for their SAS voyage was financial preparation.Overall, ten $(12.5 \%)$ participants reported this theme, however, there was minimal variation in student responses for this theme. Most of the students indicated that they worked more than one job to save money for the program. One student mentioned, "I worked two jobs to save as much money as possible to pay for the SAS program." Another student specified, "I filled out scholarship applications and saved money for the SAS program." Moreover, a few students mentioned that in addition to saving money, they fundraised for their trip.

\section{Cognitive Preparations}

The fourth theme included preparation strategies related to mental framing and goal setting for the study abroad experience. Seven participants $(8.7 \%)$ reported preparation strategies that were consistent with this theme. One student mentioned that they "tried to set goals while traveling." Likewise, another student mentioned that they "set up goals [and] made study abroad plans." Other students focused more on the mental preparations, including the student who explained, "I told myself that I would make this a trip to remember" and another student who said they"tried to mentally prepare for leaving for 4 months."

\section{Relational Preparation}

Participant responses that were consistent with the fifth theme addressed activities aimed at relationship maintenance with family and friends. Overall, six students (7.5\%) provided responses that were consistent with this theme. 
Responses in this theme were rather similar and related to students preparing to be gone from their friends and family. Students said they "spent time with family" and "emotionally talked to friends and family."

\section{Reliance on Previous Experience/No active preparation}

The final theme reflects students who relied on previous travel experiences, or reported no active preparation. A small number of students in the study reported that they did not prepareto any degree for their study abroad travel.

Moreover, three students indicated that they did not prepare and instead relied on their previous international experiences as preparation for the study abroad experience. For example, one student explained, "I have traveled to various places since I was a kid, so I have gradually prepared for it." Another student mentioned, "As a person from Hong Kong, I have studied in the US for 3.5 years before participating in SAS." The third participantmentioned their volunteer work in Puerto Rico and the Dominican Republic as preparation for their voyage.

\section{Discussion}

The goal of the present study was to examine the ways that students self-prepare prior to leaving for a study abroad program. The findings indicate that a majority of the participants engaged in at least one or more preparation activities before departing on their SAS voyage. Furthermore, the data indicate that students were more likely to engage in certain preparatory activities over others. For example, most students reported engaging in acquiring knowledge and logistical planning, while other aspects like cognitive preparation and relational preparation were less likely to be reported.

Scholars have argued that students need "intense and systematic guidance" prior to study abroad excursions in orderto reap the full benefits associated with global education experiences (Kruse \& Brubaker, 2007). Our findings provide insights into what students do to prepare when left to their "own devices," which are consistent with what most predeparture orientations focus on (Kruse \& Brubaker, 2007), the logistical aspects of preparation. However, Kruse and Brubaker (2007) make a strong case for the importance of moving beyond these logistical aspects in order to teach students how to become "effective culture learners" prior to their departure. In that way, students are prepared to get the most out of their study abroad experience. Similarly, Jones, Rowe, and Miles, (2018) argue that although the practical and logistical components of preparation are important, educators need to put more energy into the "cognitive" domain of preparation by encouraging students to adopt a critical mindset for study abroad travel. Moreover, qualitative findings from Jones et al. (2018) suggest that developing a more critical lens (e.g., Cognitive Preparation) prior to study abroad excursions can enhance students' ability to see themselves as "cultural actors," resulting inan increasedability to integrate their experiences into future cross-cultural practices (Jones et al., 2018).Other scholars have noted the exploration of one's cultural identity as a key factor that facilitates cross-culture competence (Root \&Ngampornchai, 2012). Unfortunately, the cognitive aspects of preparation were reported by a very small percentage of the participants in the current study, thus supporting the need to further orient students in this domain.

Previous research has also found that students conceptualize prior travel/international experience, relational support, and financial assets as resources for study abroad participation (Green, Gannaway, Sheppard, \&Jamarani, 2015), all of which mirror the domains of self-preparation articulated by the participants in the present study. It has also been suggested that the resources and preparation that students have prior to study abroad excursions are linked to privilege (Green et al., 2015). In other words, students with more international experience, support from family and friends, and economic resources may come from backgrounds that provide increased access to these resources that may not be available to students of other backgrounds. Findings from the present studyon how students' self-prepare support the notion that purposeful pre-departure preparation may serve as a way to "democratize" study abroad participation and experiences. If faculty members adequately prepare students for what to expect, once the students are in the host country, all students can equally take advantage of the experience. Moreover, our findings suggest that few students cognitively prepare on their own, therefore study abroad programs may need to provide students with deeper cognitive preparation. This may help to better set up students to be successful who do not necessarily have previous travel experiences to rely on.

Based on the finding that many of the participants relied on online research as their method of preparation, the researchers suggest that more guidance might be needed for students in their reliance on online resources. Some virtual resources may not have accurate or up-to-date information regarding study abroad destinations. Therefore, supporting students to be more effective and strategic in their knowledge generation when it comes to online sources can help them to be more effective consumers ofinformation that is found online. Study abroad programs and partnering institutions could consider supplementing students' own research with specific websites, Youtubevideos, and blog posts that are deemed accurate and up-to-date, since students appeared to value and rely heavily on these more "modern" types of preparatory material. Furthermore, making sure that students are addressing multiple aspects of the study 
abroad experience and not just focusing on one area in their research is also key. Perhaps providing students with a list of topics they should research would help to ensure that they are acquiring information on broad range of areas. Other scholars (Dunlap \&Mapp, 2017) agree that providing students with a framework from which to prepare for and process their study abroad experiences is critical for positive student outcomes.

Although previous research has linked past travel experience to positive study abroad outcomes (e.g., enhanced global perspective) (McCabe, 1994), it is also important to consider that students who rely too much on prior travel experience or their international student status as preparation might need encouragement to see their preparatory activities in a broader manner. Particularly, previous international experiencein one country may not adequately prepare students for the diverse and assorted cultures students are immersed in during the SAS program.

Additionally, pre-departure preparation provides an opportunity to clarify how study abroad differs from tourism. Deeper cognitive preparation guided by faculty that involves goal setting, personal reflection, and analysis of one's own cultural competence may set students up to dive deeper into their study abroad experience as active participants.

\section{Limitations}

Although the data generated from this study add to a limited area of research, the present study is not without limitations. The study sample was homogeneous in terms of racial/ethnic background, age and gender, limiting the generalizability of findings to other more diverse groups of students.In addition, the qualitative responses were generally brief and varied in the degree of detail as to what students focused on during their preparation. Conducting one-on-one interviews or focus groups mayhave yielded more descriptive and detailed data. Consequently, we did not have specific information on what students implied when they mentionedengaging in "knowledge gathering" activities. For example, students may have focused on specific areas on the SAS website, online blogs, and discussions with study abroad alumthat were not captured in their short responses. Finally, our data did not provide information on how useful the specific types of preparation were for students during their experience abroad.

\section{Future Directives/Implications}

Previous research on study abroad programs demonstrates the importance of effective student preparation prior to departure. The present study expands upon the existing research, which is largely steeped in how faculty can prepare students to include students' perspectives of their own preparatory activities. The findings from this study have implications for future research on study abroad, as well as for the structure and pedagogy of study abroad programs. For example, using a more diverse group of participants, future research should investigate the connections between demographic variables and preparation activities. This will provide valuable insight into student self-preparation and their respective access to resources. Additionally, researchers should examine the relationship between particular preparatory activities and student outcomes. More specifically, examining how various domains of preparation are linked to the overall abroad experience, cultural sensitivity and global mindedness is needed. Qualitative research with students after study abroad travel should examine the preparatory activities they found most useful and why. The researchers of the present study also believe that the domains of self-preparation that emerged from the data can serve as the foundation for developing quantitative assessments of student self-preparation. Lastly, in light of the limited attention given to areas of preparation like cognitive planning and relational planning, study abroad faculty and program leaders should be more attentive to supporting their students with preparatory efforts in these domains.

\section{References}

Bikos, L. H., Manning, S. B., \&Frieders, Z. J. (2019). Ready or not here I come: A qualitativeinvestigationof students' readiness perceptions for study abroad/away. International Perspectives in Psychology: Research, Practice, Consultation, 8(2), 78.

Caton, K., \& Santos, C. A. (2009). Images of the other: Selling study abroad in a postcolonial world. Journal of Travel Research, 48(2), 191-204.https://doi.org/10.1177/0047287509332309.

Dukes, R. L. (2006). Reflections on the meaning of the semester at sea voyage after twenty-two years. Psychological Reports, 98(1), 209-216.

Dunlap, A. \&Mapp, S. C. (2017). Effectively preparing students for international field placements through a predeparture class. Social Work Education, 36(8), 893-904.

Eisner, E. W. (1998). The enlightened eye: Qualitative inquiry and the enhancement of educational practice. Upper Saddle River, NJ: Merrill.

Fang, F., \& Baker, W. (2018). 'A more inclusive mind towards the world': English language-teaching and study abroad in China from intercultural citizenship and English as a lingua franca perspectives. Language Teaching Research, 22(5), 608-624. 
Fietzer, A. W., Ponterotto, J. G., Jackson, M. A., \&Bolgatz, J. (2016). Cultural adjustment andsocialjustice behaviour: The role of individual differences in multicultural personality. European Journal ofPersonality, 30(6), 552563.

Green, W., Gannaway, D., Sheppard, K., \&Jamarani, M. (2015). What's in their baggage? The cultural and social capital of Australian students preparing to study abroad. Higher Education Research \& Development, 34(3), 513-526.

Goldoni, F. (2015). Preparing students for studying abroad. Journal of the Scholarship of Teaching and Learning, $15(4), 1-20$.

Harder, A., Andenoro, A., Roberts, T. G., Stedman, N., Newberry III, M., Parker, S. J., \&Rodriguez, M. T. (2015). Does study abroad increase employability?. NACTA Journal, 59(1), 41.

Harris, V. W., Kumaran, M., Harris, H. J., Moen, D., \& Visconti, B. (2019). Assessing multicultural competence (knowledge and awareness) in study abroad experiences. Compare: A Journal of Comparative and International Education, 49(3), 430-452.

Jones, P., Rowe, S., \& Miles, D. (2018). Beyond practical preparation: A critical approach to preparing social work students for international study experiences. International Social Work, 61(6), 1083-1094.

Koernig, S.K. (2007). Planning, organizing, and conducting a 2-week study abroad trip for undergraduate students: Guidelines for first-time faculty.Journal of Marketing Education, 29(3), 210-217. DOI: $10.1177 / 0273475307306886$.

Kruse, J., \& Brubaker, C. (2007). Successful study abroad: Tips for student preparation,immersion, and postprocessing. Die Unterrichtspraxis/Teaching German, 40(2), 147-153.

Leung, A. K. Y., Maddux, W. W., Galinsky, A. D., \& Chiu, C. Y. (2008). Multicultural experience enhances creativity: The when and how. American Psychologist, 63(3), 169.

Lewis, T. L., \&Niesenbaum, R. A. (2005). Extending the stay: Using community-based research and service learning to enhance short-term study abroad. Journal of Studies in International Education, 9(3), 251-264.

Luo, J., \& Jamieson-Drake, D. (2016). Predictors of study abroad intent, participation, and college outcomes. Research in Higher Education, 56(1), 29-56. doi:10.1007/s11162-0149338-7.

Lumkes Jr, J. H., Hallett, S., \&Vallade, L. (2012). Hearing versus experiencing: The impact of a short-term study abroad experience in China on students perceptions regarding globalization and cultural awareness. International Journal of InterculturalRelations, 36(1), 151-159.

McCabe, L. T. (1994). The development of a global perspective during participation in semester at sea: A comparative global education program. Educational Review, 46(3), 275-286.

Medora, N., \& Roy, N. (2017). Recruiting, organizing, planning, and conducting a 3-week, short-term, Study Abroad program for undergraduate students: Guidelines and suggestions for first-time faculty leaders. International Journal of Humanities and Social Science Research, 3, 1-11. doi:10.6000/2371-1655.2017.03.01

Montgomery, J. F., \&Arensdorf, J. (2012). Preparing globally competent leaders through innovative study abroad experiences. Journal of Leadership

Norris, E. M., \& Gillespie, J. (2012). How study abroad shapes global careers: Evidence from the United States. Journal of Studies in International Education, 13, 382-397.

Rios, K., \& Wynn, A. N. (2016). Engaging with diversity: Framing multiculturalism as a learning opportunity reduces prejudice among high White American identifiers. European Journal of Social Psychology, 46(7), 854-865.

Root, E., \&Ngampornchai, A. (2013). "I Came Back as a New Human Being" student descriptions of intercultural competence acquired through education abroad experiences. Journal of Studies in International Education, 17(5), 513-532. 